\title{
Evaluation of Kinetic Parameters for Bio Hydrogen Production by Anaerobic Suspended Growth Reactor Using Synthetic Feed and Up Scaling Anaerobic Suspended Growth Reactor Using Complex Feed
}

\author{
R.Hema Krishna (Corresponding author) \\ Department of Chemistry, Nimra Institute of Science and Technology, India \\ E-mail: hkravuri32@gmail.com; rhksastry@yahoo.co.in \\ S.Venkata Mohan \\ Indian Institute of Chemical Technolog, B.E.E.C, India \\ E-mail:vmohan_s@yahoo.co \\ A.V.V.S.Swamy \\ Department of Environmental Sciences, Acharya Nagarjuna Uuniversity, India \\ E-mail: drswamyvvsarza@yahoo.com
}

Received: October 25, 2010 Accepted: November 9, 2010 doi:10.5539/ijc.v3n2p124

\begin{abstract}
The objective of the present study is the Evaluation of Kinetic Parameters for hydrogen production by anaerobic suspended growth reactor using synthetic feed and Up scaling Anaerobic suspended growth reactor using complex feed. Hydrogen production through anaerobic fermentation of synthetic feed was then studied in an up flow suspended film batch reactor. Synthetic feed consists of specific concentrations of several nutrients required for anaerobic fermentation. The process parameters were set depending on the optimization studies. This process aimed at establishing hydrogen production in a 1 liter suspended reactor. Similar studies were performed in a suspended growth anaerobic system (stirred tank reactor) having an in-built turbine and operated by a magnetic stirrer. The hydrogen production was monitored and sequencing results were used to estimate the kinetic parameters of the reaction. The suspended growth anaerobic system was fed with optimized substrate. The reactor operation was monitored by monitoring the process parameters such as $\mathrm{pH}, \mathrm{ORP}$, VFA, etc. The anaerobic stirred tank reactor showed consistency in its results on feeding with the synthetic feed. This set of experiments aims at studying the variation of process parameters on using the optimized co-substrate and nitrogen source as the feed for the reactor. The complex feed containing sucrose and DAP for Up scaling Anaerobic suspended growth reactor.
\end{abstract}

Keywords: Synthetic feed, Complex feed. pH, COD, VFA, HPLC, Bio-hydrogen

\section{Introduction}

Today environmental pollution is a great concern to the world due to rapid industrialization and urbanization. So increasing focus is being placed on "clean energy" alternatives for satisfying growing energy demand. Energy is vital global prosperity, yet dependence on fossil fuels as our primary energy source contributes global climate change, environmental degradation, and health problems. A fundamental and principal difficulty of the future energy supply is that the formation of fossil fuels is much slower than the rate of their exploitation (Kovacs et al 2000).The popularity of Hydrogen as a fuel source followed from a crisis that resulted on greater usage of non-renewable fuels. During the Energy crisis of the 1970's, Hydrogen was touted as the "fuel of the future" and a great deal of time and money were put on research on its possible sources and applications. The biological hydrogen production was first seriously considered as a practical capability through a series of sponsored meetings conducted by National Science Foundation, Washington D.C. (Gibbs et. al. 1973).

Studies in laboratory have concentrated on pure substrates including glucose, starch and cellulose, often in batch processes. Volatile Fatty acids have long been recognized as intermediates in anaerobic process and have been 
proposed as a control parameter. (Ahning et. al., 1997) Major volatile fatty acids detected in the anaerobic process were acetate, propionate and butyrate. Fermentations of hexose to acetate or butyrate produce $\mathrm{H}_{2}$ and $\mathrm{CO}_{2}$. Fermentations to propionate or lactate produces no hydrogen. Reduced fermentation end products such as ethanol and other alcohols contains additional $\mathrm{H}$ atoms not present in corresponding acids and therefore alcohol production gives correspondingly low $\mathrm{H}_{2}$ yields. It is important, therefore, to establish bacterial metabolism resulting in acetate and butyrate as end products. Sustained hydrogen production coupled with bacterial growth was achieved by continuous addition of small amounts of glutamate, $\mathrm{NH}_{4}{ }^{+}$or $\mathrm{N}_{2}$. (Fascetti and Todini, 1995) A gradual production of acids depleted the buffering capacity of these substances resulting in a concomitant decline in $\mathrm{pH}$ to about 5.5 before hydrogen production began. In stationary growth phase, the acetate production decreased slightly but an increase in butyrate production was noticed. For an optimum $\mathrm{pH}$ range of 5.5-5.7, the acetate to butyrate production ratios was found in the range of 3-4 for substrates like sucrose and starch. (Khanal et. al., 2004) Fermentative hydrogen evolution is considered more advantageous than other hydrogen generation processes. It was also found possible to increase the conversion efficiency from $10 \%$ to $28 \%$ by using proportionate mixtures of various waste materials and effluents from industrial processes, which also facilitated waste recycling. (Kumar et. al., 2001) The efficiency of a hydrogen-producing bioprocess also highly depends upon the optimal control of factors like ratio of substrate concentration to biomass concentration. The ratio significantly influences the metabolic and kinetic characteristics of microorganisms. (Chudoba et. al., 1992) However, there are still no reports demonstrating the uses of kinetic models and describing and predicting the exact kinetic characteristics of batch anaerobic hydrogen-producing cultures. It is a known fact that normal biological processes are operated at ambient temperatures $\left(30-40^{\circ} \mathrm{C}\right)$ and normal pressure, which are considered to be less energy intensive. Optimized Hydrogen production from Industrial effluents especially those from the pharmaceutical units through anaerobic technology are considered very important because the real problem in a treatment system is not only the actual content of the wastewater, but also its quantity and quality. The present investigation shows the anaerobic stirred tank reactor showed consistency in its results on feeding with the synthetic feed and complex feed.. This set of experiments aims at studying the variation of process parameters on using the optimized co-substrate and nitrogen source as the feed for the reactor. The complex feed containing sucrose and DAP for Up scaling Anaerobic suspended growth reactor.

\section{Experimental work}

\subsection{Analytical Procedures}

The performance of reactor with synthetic feed was assessed by monitoring carbon removal (COD) throughout the reactor operations and during the cycle period. In addition, $\mathrm{pH}$, oxidation-reduction potential (ORP), VFA, Alkalinity and suspended solids (SS) were determined during reactor operation to assess the performance of the reactor. The analytical procedures for monitoring the above parameters were adopted from the procedure outline in the Standard methods. The method performed for determination of physicochemical parameters was adopted from standard methods of American public health association (APHA, 2000).

\subsection{Glucose Estimation}

Glucose concentration in the culture medium was determined spectrophotometrically by DNS (Dinitro salicylic acid) method basically according to Miller. DNS Reagent: Dissolve by stirring $1 \mathrm{~g}$ of DNS, 200mg of crystalline phenol and $50 \mathrm{mg}$ sodium sulfite in $100 \mathrm{ml} 1 \% \mathrm{NaoH}$. Store at $4^{0} \mathrm{C}$. A volume of 0.1 and $0.2 \mathrm{ml}$ of sample should be collected into a clean test tube. The volume was made up to $1 \mathrm{ml}$ with distilled water. $2 \mathrm{ml}$ of DNS solution was added to each tube and kept in boiling water bath for 5 minutes. The resulting mix was made up to $10 \mathrm{ml}$ with distilled water. The absorbance at 540 was recorded against the blank without glucose. A graph has been plotted against Optical Density Vs concentration.

\subsection{Volatile Fatty Acids (VFA)}

Monocarboxylic acids like acetic acid, Proponoic acid, butyric acid, etc; and polycarboxylic acids like lactic acid, succinicacid, etc are known as volatile fatty acids (VFA). These acids under anaerobic conditions decompose to give carbon dioxide and methane. If methanogenic bacteria are inhibited and the process of decomposition is controlled at Acidogenesis hydrogen gas is produced.

\subsection{Chemical Oxygen Demand (COD)}

Reagents:

1)Standard potassium dichromate $(0.25 \mathrm{~N}): 12.259 \mathrm{~g}$ of $\mathrm{K}_{2} \mathrm{Cr}_{2} \mathrm{O}_{7}$ was dried at $103^{\circ} \mathrm{C}$ for 24 hours in distilled water and diluted to $1000 \mathrm{ml} .2$ )Sulphuric acid reagent: $10 \mathrm{~g}$ of $\mathrm{AgSO}_{4}$ was dissolved in $1000 \mathrm{ml}$ concentrated sulphuric acid, and kept over night for dissolution.3)Standard ferrous ammonium sulfate- $0.1 \mathrm{~N}$ : $39.0 \mathrm{~g}$ of Fe $\left(\mathrm{NH}_{4}\right)_{2} \mathrm{SO}_{4} 6 \mathrm{H}_{2} \mathrm{O}$ was dissolved in about $400 \mathrm{ml}$ distilled water. $20 \mathrm{ml}$ of concentrated conc. $\mathrm{H}_{2} \mathrm{SO} 4$ was added. 
Cooled and made unto $1 \mathrm{~L}$ and standardized with $\left.\mathrm{K}_{2} \mathrm{Cr}_{2} \mathrm{O}_{7}(0.25 \mathrm{~N}) 4\right)$ Ferroin indicator: $1.485 \mathrm{~g}$ of 1,10 phenanthrolin monohydrate and $0.695 \mathrm{~g} \mathrm{FeSO}_{4} 7 \mathrm{H}_{2} \mathrm{O}$ was dissolved in distilled water and diluted to $100 \mathrm{ml}$ with distilled water.5)Mercuric sulfate: $\mathrm{HgSO}_{4}$ crystals (analytical grade) were used.1 $\mathrm{ml}$ of the sample was taken in $10-\mathrm{ml} \mathrm{COD}$ vials and to this $1 \mathrm{ml}$ distilled water, $2 \mathrm{ml} \mathrm{K}_{2} \mathrm{Cr}_{2} \mathrm{O}_{7}$ solution and $4 \mathrm{ml} \mathrm{H}_{2} \mathrm{SO}_{4}$ reagents were added. These vials were kept in COD block digester and refluxed for a period of 2 hours at $150^{\circ} \mathrm{C}$. After refluxing was completed the samples were cooled and were transferred into $100 \mathrm{ml}$ beaker. Then 2 to 3 drops of ferroin indicator was added to sample solution and titrated against $0.1 \mathrm{~N}$ FAS, until brick red color appeared. COD was calculated by using the following formula. Color, turbidity and silica in the concentration of $500 \mathrm{ppm}$ interfere in this estimation. Filtration can be done to remove color and turbidity.

$$
\operatorname{COD}(\mathrm{mg} / \mathrm{l})=\frac{(\mathrm{B}-\mathrm{S}) * \mathrm{~N} * 8000}{\mathrm{ml} \text { of sample taken }}
$$

Where, $\mathrm{B} \mathrm{ml}$ is amount of FAS consumed for blank, $\mathrm{S} \mathrm{ml}$ is FAS consumed for sample, $\mathrm{N}$ is normality of FAS( Ferrous ammonium sulphate).

\subsection{Hydrogen production in a stirred tank reactor maintained under suspension}

The innoculum from the suspended reactor was directly transferred to a stirred tank reactor fitted with a 2-blade axial turbine consisting of a magnetic pellet that can be operated with the help of a magnetic stirrer. This reactor maintained a suspension by the movement of the turbine blades, which stirred the microbial culture to move in the working volume in an irregular manner. Reactor start up, this reactor did not have a startup procedure because the innoculum was taken directly from the suspended reactor, which was recently treated to inhibit methanogenesis. Reactor setup and inlet conditions, the reactor has a total working volume of 1.25 -liter capacity. The hydrogen fermentation was conducted at mesophilic temperature $\left(29 \pm 2{ }^{0} \mathrm{C}\right)$. The $\mathrm{pH}$ was maintained at 6 to ensure that the fermentation process does not yield a drastic drop in the $\mathrm{pH}$ value after a HRT of 24 hours. This decision was based on the optimization studies. The suspension was maintained by the movement of turbine blades powered by a magnetic stirrer operating at $100 \mathrm{rpm}$.

\subsection{Synthetic feed studies-Reactor operation}

The reactor was started with synthetic feed, which has the composition as shown in Table 1. About 1 liter of synthetic feed was taken and fed to the reactor and the inlet and outlet samples (after a HRT of 24 hours) were collected and was continuously examined for $\mathrm{pH}$, ORP, VFA, COD and hydrogen gas production. The reactor was analyzed for the various important process parameters for the inlet and outlet samples for around 13 days. After a steady state was attained, the sequencing at the HRT intervals of 1, 2, 4, 6, 8, 10, 12, 24 and 48 Hours of incubation. The samples were regularly monitored for $\mathrm{pH}$, VFA, Alkalinity, COD, Glucose, VSS and Hydrogen gas parameters. HPLC for the samples was carried out. The reactor kinetics and substrate conversion efficiency was also calculated using the biomass and substrate concentrations at various time intervals in sequencing period.

\subsection{Complex feed studies-Reactor operation}

Complex feed refers to the variable concentrations of nutrients required to enhance fermentation and hydrogen production process. Based on optimization studies, the complex feed was specified as shown in the Table 2 . The sucrose concentration was calculated to maintain an organic loading rate of approximately $5000 \mathrm{mg} / \mathrm{l}$. DAP concentration was based on N: P ratio of 5:1. About 1 liter of the feed was taken and fed to the reactor and the inlet and outlet samples (after a HRT of 24 hours) were collected and was continuously examined for $\mathrm{pH}$, ORP, VFA, COD and hydrogen gas production. The reactor was analyzed for the various important process parameters for the inlet and outlet samples for around 3 days. After a steady state was attained, the sequencing at the HRT intervals of $1,2,4,6,8,10,12,24$ and 48 Hours of incubation. The sequencing samples were monitored for $\mathrm{pH}$, VFA, Alkalinity, COD, Sucrose and Hydrogen gas parameters. HPLC for the samples was carried out. The substrate conversion efficiency was also calculated at various time intervals in sequencing period.

\subsection{Hydrogen Gas Estimation}

Hydrogen gas produced in the reactor is estimated using a gas sensor, FMK satellite 4-20 mA version (ATMI $\mathrm{GmBH}$ Inc.). This equipment is a generic gas-monitoring instrument with microprocessor based electronics interfacing with std. 4 to $20 \mathrm{~mA}$ alarm/control systems. Target gas and measuring range depend on type of sensor chosen.The electrochemical sensors designed for use with the FMK satellite feature an integrated data memory. When a new sensor is fitted, the instrument's electronics will load operating parameters of the sensor into microprocessor's memory. The current flowing through the sensor is amplified electronically, digitized and 
temperature compensated and resulting concentration value is given as an analog 4 to $20 \mathrm{~mA}$ output signal. This output signal usually displays the \%volume of hydrogen in the reactor air space.

\section{Results and discussion}

\subsection{Anaerobic suspended growth reactor using synthetic feed}

The reactor operation was monitored by monitoring the process parameters such as $\mathrm{pH}$, ORP, VFA, etc. The inlet $\mathrm{pH}$ was maintained at 6.0 throughout the study while the outlet $\mathrm{pH}$ remained almost constant (4.1) with only variation of 3.9 at the $5^{\text {th }}$ day as shown in figure 1 Little variation was found in $\mathrm{pH}$ representing a steady state condition achieved by the reactor resulting in better performance in comparison with the up flow reactor studies. The inlet VFA concentration as shown in figure. 2, lies within the range of (1987 to $2416 \mathrm{mg} / \mathrm{L})$ while outlet recorded a minimum of $2295 \mathrm{mg} / \mathrm{L}$ on the $7^{\text {th }}$ day and a maximum of $2720 \mathrm{mg} / \mathrm{L}$ on the $6^{\text {th }}$ day. VFA showed an increase of 300-400 mg/l after a HRT (Hydrogen Reactor Time intervals) of 24 hours. There was a regular increase in the outlet VFA value representing the VFA accumulation within the system, which is responsible for the relative decrease in the $\mathrm{pH}$ within the system. The variation in VFA explicitly proves the consistent performance of the system further aided by the study on the hydrogen production rate. In this system, the alkalinity values are well within the range of 0 to $840 \mathrm{mg} / \mathrm{L}$ with a number of readings constant at $120 \mathrm{mg} / \mathrm{L}$. The zero alkalinity indicates the increase in buffering capacity of the system to counteract VFA formation and maintain equilibrium. The zero alkalinity was found only on days 7, 8 and 10 where the VFA conversion was greater. The studies indicate a highly varying COD reduction $\%$. The COD reduction $\%$ values varied between a range of $21 \%$ to a high value of $70 \%$ indicating greater performance by the system. The COD reduction $\%$ values shown in figure 3, however, showed an average of around 30\% throughout the experimental period. The inlet COD was maintained at an average of around $5000 \mathrm{mg} / \mathrm{L}$.

The hydrogen production rate is calculated is shown in figure 4 . The hydrogen production rate increased in the first 3 days to around $0.32 \mathrm{mmol} /$ day that is considered very good taking into account that only 3 days were given for the acclimation of the culture to the system. Then, the hydrogen rates slowly decreased to 0.02 $\mathrm{mmol} / \mathrm{day}$ at the end of 7 days showing depletion in the performance of the system. Further, the culture acclimatized to the system increasing hydrogen production rates to $0.49 \mathrm{mmol} / \mathrm{day}$ with consistency being maintained in the other process parameters. The sequencing experiment aimed at deciding the success ratio of the experiment with an anaerobic stirred tank reactor. The parameters analyzed during the sequencing procedure were used to calculate the kinetic model parameters for hydrogen production through the anaerobic fermentation of glucose.

The variation of $\mathrm{pH}$ as depicted in figure. 5 shows a drop from 5.7 at the $0^{\text {th }}$ hour to 4 at the end of $8^{\text {th }}$ hour followed by a small increase to 4.1 at the end of $10^{\text {th }}$ hour and remained constant until the end of sequencing period. The $\mathrm{pH}$ values remained very low at the end of the sequencing period indicating the decrease in system's performance in acidogenic fermentation process.

The variation in VFA as shown in figure. 6 showed a constant increase from $2052 \mathrm{mg} / \mathrm{L}$ at the $0^{\text {th }}$ hour to around $2661 \mathrm{mg} / \mathrm{L}$ at the end of $12^{\text {th }}$ hour followed by a decrease in the VFA to $2417 \mathrm{mg} / \mathrm{L}$ at the end of $24^{\text {th }}$ hour. The VFA of the synthetic feed showed a maximum value at the end of $12^{\text {th }}$ hour $(2661 \mathrm{mg} / \mathrm{L})$. The VFA variation indicates a stable performance of the system till the $12^{\text {th }}$ hour where the process encounters inhibitory action finally ending up with a comparatively reduced performance. The alkalinity values also decreased from 360 $\mathrm{mg} / \mathrm{L}$ at the $0^{\text {th }}$ hour to $0 \mathrm{mg} / \mathrm{L}$ at the end of $2^{\text {nd }}$ hour after which stability remained indicating consistent VFA formation until the $12^{\text {th }}$ hour. Then the alkalinity values also started increasing finally showing $60 \mathrm{mg} / \mathrm{L}$ at the end of the reaction period. The COD reduction \% values indicated multiple variations in its values as shown in figure 7. This caused difficulties in discussing the variation of the COD reduction \% values. But it can be stated that an increase in COD reduction \% was witnessed at the end of the reaction period. The variation in hydrogen production complies with that discussed under the variation of VFA and alkalinity. The hydrogen production as shown in figure. 8 rate decreased to $0 \mathrm{mmol} / \mathrm{hr}$ at the end of 24 hours from a value of $0.086 \mathrm{mmol} / \mathrm{hr}$ measured in the $12^{\text {th }}$ hour. This indicates a decrease in system's performance. However, the hydrogen production rate increased from $0 \mathrm{mmol} / \mathrm{hr}$ in the $0^{\text {th }}$ hour to $0.1 \mathrm{mmol} / \mathrm{hr}$ at the $8^{\text {th }}$ and $10^{\text {th }}$ hours before starting to decrease to lower values. The system's performance required kinetic study to establish conclusions.

\subsection{Kinetic Parameters Evaluation}

For a batch reactor operated with mixing, the control volume consists of the entire reactor. Components in the reactor are distributed uniformly throughout the reactor so that concentration of any component is the same at any location within the reactor at any time. We select components as the bacteria (anaerobic mixed culture) and their rate-limiting substrate, which is frequently the electron donor, as our choice here. We assume that all the other 
bacterial requirements like the electron acceptor and nutrients are sufficiently high in concentration, as they impose no limitations on organism growth rate.Kinetic model parameters are usually based on the substrate consumption rate and bacterial cell growth rate. Kinetic model parameter for a $24 \mathrm{hr}$ HRT (by sequencing procedure) has not been attempted in the past because of its invariably low results. Theoretically, the cell growth rate is expressed as

$$
\rightarrow \mathrm{dX} / \mathrm{dt}=\mu * \mathrm{X}
$$

Where, $\mathrm{X}$ is the cell dry weight concentration $(\mathrm{g} / \mathrm{l})$ and $\mu$ is the specific growth rate $\left(\mathrm{h}^{-1}\right)$, which might depend on substrate concentration and the other factors. Several models provide an expression for $\mu$, the Monod expression being the most common. The profile of hydrogen concentration and glucose utilization with time shown in figure. 9 indicates that the kinetics of product formation and disappearance of reactants is in acceptance with the stoichiometry of the reaction. The graph of substrate concentration and biomass concentration with respect to time was also plotted to show whether the reaction stoichiometry has been satisfied (Koku et. Al., 2003). The $\mu$ values calculated from procedure are given in the Table 3 . The bacterial culture in the stirred tank suspension reactor is considered to be in the exponential phase through the study of variation of sludge dry weight (VSS) with time studied during sequencing period. The VSS values showed a small increase in the first 2 hours followed by an exponential growth till the $12^{\text {th }}$ hour is shown in figure 10. The VSS of the sludge than recorded the maximum value $\left(\mathrm{X}_{\max }\right)$ of $27.2 \mathrm{~g} / \mathrm{L}$ at the end of $24^{\text {th }}$ hour.

The growth rate in the exponential phase is assumed to be constant.Therefore, (1) gives,

$$
\mu_{\mathrm{c}}=\ln \left(\mathrm{X}_{2} / \mathrm{X}_{1}\right) /\left(\mathrm{t}_{2}-\mathrm{t}_{1}\right)
$$

Where, $\mu_{\mathrm{c}}$ is the specific growth rate in the exponential phase and $\mathrm{X}_{1}, \mathrm{X}_{2}$ are the two distinct cell concentrations in the exponential phase $(\mathrm{g} / \mathrm{l})$.Now, a logistic model is used, which has the additional benefit of representing the entire growth curve, including the lag phase (if present), the exponential growth and the stationary phases. The specific growth rate for the logistic model is

$$
\mu=\mathrm{k}_{\mathrm{c}}\left(1-\mathrm{X} / \mathrm{X}_{\max }\right)
$$

The logistic model parameters $\left(\mathrm{k}_{\mathrm{c}}\right.$ and $\left.\mathrm{X}_{\max }\right)$ and $\mu_{\mathrm{c}}$ values were then recorded in a table. The graph of total hydrogen production versus time was plotted and the $\mathrm{R}^{2}$ value was used as a measure of goodness of fit is shown in figure 11. The profile of hydrogen produced $(\mathrm{ml})$ versus time (hrs) gave a variance curve for which a curve is fitted to measure the $\mathrm{R}^{2}$ value. The $\mathrm{R}^{2}$ value, which quantifies the dispersion of distribution from the mean, is used as a measure of goodness of fit. It was found that the $\mathrm{R}^{2}$ value for the model was $79 \%$ indicating a close agreement of the model to experimental data. However, the $\mathrm{R}^{2}$ values for fermentation of glucose using a pure culture of photosynthetic bacteria was reported above $98 \%$ (Koku et. Al., 2003).Two conventions were used for expressing the gas production rate in this study. The first is the average gas production rate per bacterial dry weight $\left(r^{\prime}{ }_{g}\right)$, which is calculated by time averaging of individual rates and has the unit of $1 / g / h$. The individual rates obtained for a certain period were calculated by dividing the volume increment of the gas produced by average cell concentration and by the duration of that period. The second convention is the average gas production rate per culture volume $\left(\mathrm{r}_{\mathrm{g}}\right)$, which is calculated by dividing the total volume of gas produced by the volume of culture and by the duration of gas production, and has the unit $1 / 1 / h$ (Koku et. Al., 2003). These two parameters were calculated and recorded in the Table 3 . Another important variable necessary for kinetic study is the biomass yield as shown in fig. 12. The variation of biomass yield $(\mathrm{Y})$ with time showed a drastic decrease at the end of $2^{\text {nd }}$ hour followed by a gradual decrease indicating that the biomass used less amount of substrate for its growth when compared with that utilized for hydrogen production. This can be measured by determining the substrate conversion efficiency $(\eta)$. A particular useful parameter for characterizing microbial hydrogen production is the substrate conversion efficiency, which is the ratio of the actual amount of hydrogen evolved to the amount expected through stoichiometric conversion of the substrate (Hillmer and Gest, 1977). This is due to the belief that the portion of substrate initially utilized for biosynthesis can eventually end up as a substrate for hydrogen production (Koku et. Al., 2003).

For glucose, which is the primary carbon substrate used in this study, 4 moles of hydrogen are expected to be produced per mole of glucose utilized, so the substrate conversion efficiency $(\eta)$ is

$$
\eta=100 * \mathrm{P} / 4 * \mathrm{~V} * \mathrm{~S}_{0}
$$

Where, $\mathrm{P}$ is the moles of hydrogen produced till that time and $\mathrm{V}$ is the culture volume in liters (Koku et al., 2003). The substrate conversion efficiency attained maximum value at the end of $24^{\text {th }}$ hour with a value of $6.34 \%$. The substrate utilization rate $\left(\mathrm{k}_{\mathrm{s}}\right)$ is also calculated and listed in the Table 3. The substrate conversion efficiency of glucose assuming $4 \mathrm{~mol}$ of hydrogen per mole of glucose consumed was studied to show a maximum value of 
$23 \%$ using pure cultures. However, the experiments were conducted for around 8 to 15 days. No previous experiments have been conducted to find the substrate conversion efficiency during the sequencing period of 24 hours. VFA evaluation through HPLC indicated presence of acetic acid and propionic acid within the system, which could be the possible substrate for hydrogen production is shown in figure 13

\subsection{Upscaling Anaerobic suspended growth reactor using complex feed}

The anaerobic stirred tank reactor showed consistency in its results on feeding with the synthetic feed. This set of experiments aims at studying the variation of process parameters on using the optimized co-substrate and nitrogen source as the feed for the reactor. The complex feed containing sucrose and DAP was calculated to maintain a COD value of $5000 \mathrm{mg} / \mathrm{L}$. The initial $\mathrm{pH}$ was maintained at 6 . The final $\mathrm{pH}$ showed a constant value (4.1) indicating consistency in anaerobic fermentation of the feed. Figure 14 shows that even though the final $\mathrm{pH}$ was low, it did not prove inhibitory for hydrogen production and VFA formation due to greater air space and lower partial pressure of hydrogen. The initial VFA of the feed varied from $1929 \mathrm{mg} / \mathrm{L}$ to $2113 \mathrm{mg} / \mathrm{L}$ as shown in figure 15. However, the VFA conversion showed constant values after a HRT of 24 hours. This consistency in VFA formation provides a perfect atmosphere for the acidogenic activity of the microbial consortia and a greater hydrogen production by the feed. Alkalinity values of the complex feed varied throughout the experiment but showed a decrease in its values at the end of 24-hour HRT throughout the experiment is shown in figure 16. The decrease in alkalinity indicated proper buffer control of the system during acid formation. The initial COD value were maintained around $5000 \mathrm{mg} / \mathrm{L}$ (in the range of $4800 \mathrm{mg} / \mathrm{L}$ to $6080 \mathrm{mg} / \mathrm{L}$ ). The COD values decreased throughout the experiment showing proper oxygen utilization for degradation of heavier organic compounds present in the feed figure 17. This is a necessary requirement for the proper functioning of the anaerobic microbial culture. The COD reduction \% also showed small variations in its values but the variation in COD reduction \% values indicated a shift of the anaerobic system towards stability. The hydrogen gas estimated showed higher variations throughout the experiment. The hydrogen production in the first two days was greater than 3.45 $\mathrm{mmol} / \mathrm{day}$ but the value decreased on the $3^{\text {rd }}$ day to $1.18 \mathrm{mmol} /$ day indicating a possible system failure. However, the hydrogen values estimated from the anaerobic fermentation of the complex feed was greater than that estimated with the synthetic feed indicating the success of the optimization studies. VFA evaluation through HPLC indicated presence of acetic acid within the system which could be the possible substrate for hydrogen production is shown in figure 18. The sequencing procedure also showed a number of variations in the process parameters especially the hydrogen production rate. The $\mathrm{pH}$ values varied from 5.6 on the $0^{\text {th }}$ hour to 4.1 at the $24^{\text {th }}$ hour. The variation in the $\mathrm{pH}$ was a constant decrease till the $8^{\text {th }}$ hour (4.1) and further onwards, a constant $\mathrm{pH}$ value was witnessed till the end of experiment.

The decrease in $\mathrm{pH}$ gives a favorable acid formation but it was studied that the production of hydrogen was affected and terminated by low $\mathrm{pH}$. The optimum $\mathrm{pH}$ range for hydrogen production being in the range of 5-6 (Ueno et. Al., 1995; Venkata Mohan et al., 2005). But in this study, though the hydrogen production was found to have a maximum value at the $\mathrm{pH}$ of 4.3 as shown in figure.19. This can be attributed to the presence of a reducing atmosphere and a healthy acid formation in the reactor. The VFA values increased throughout the sequencing period till 12 hours indicating a consistent anaerobic fermentation of the feed by the microbial consortia. The VFA value at the $0^{\text {th }}$ hour $(2173 \mathrm{mg} / \mathrm{L})$ is more than in the $1^{\text {st }}$ hour $(2115 \mathrm{mg} / \mathrm{L})$ due to presence of some amount of acids in the reactor, which adds on during sampling. However, the VFA value dipped from $3334 \mathrm{mg} / \mathrm{L}$ at the $12^{\text {th }}$ hour to $2539 \mathrm{mg} / \mathrm{L}$ at the end of $24^{\text {th }}$ hour as shown in figure. 20 indicating the fermentative inhibition of the $\mathrm{pH}$ discussed above. The alkalinity values also decreased throughout the experiment and showed an increase at the $24^{\text {th }}$ hour indicating an increase in buffering capacity of the system. This aided in decrease of acid formation and hydrogen production even though the $\mathrm{pH}$ value lied in an acidic range. The COD values showed a decreasing curve till the $6^{\text {th }}$ hour $(2080 \mathrm{mg} / \mathrm{L})$ and then increased to $2800 \mathrm{mg} / \mathrm{L}$ at the end of $8^{\text {th }}$ hour and then dropped till the end of reaction period is shown in figure. 21 . The COD reduction \% values also increased till the $6^{\text {th }}$ hour and then a drop at the end of $8^{\text {th }}$ hour followed by an increase in its values finally recording the highest value of $65.34 \%$ at the end of $24^{\text {th }}$ hour. These values indicated a healthy fermentation process throughout the sequencing period.

The hydrogen production rate values increased till the $2^{\text {nd }}$ hour and showed a small decrease at the end of $4^{\text {th }}$ hour followed by an increase till the $10^{\text {th }}$ hour where it recorded the maximum value of $0.29 \mathrm{mmol} / \mathrm{hr}$ is shown in figure.22. Then the hydrogen values dropped indicating an inhibitory process due to drop in $\mathrm{pH}$ and other factors between the $12^{\text {th }}$ and $24^{\text {th }}$ hour

\section{Summary and conclusions}

1. Kinetic model parameters for hydrogen production from synthetic feed also formed an objective for this study. The anaerobic suspended batch reactor was supplied with the pre treated anaerobic mixed culture and was fed with 
synthetic feed containing glucose as co-substrate. The anaerobic stirred tank reactor showed consistency in its results on feeding with the synthetic feed. This set of experiments aims at studying the variation of process parameters on using the optimized co-substrate and nitrogen source as the feed for the reactor. Details of hydrogen production from the experimental studyshown in table 4.

2. It is evident from the data that the suspended growth configuration has yielded hydrogen production without process inhibition, however the process of hydrogen production seems to dependent on the type of wastewater and organic loading rate. Though efficient research study has been affected in this field with a high degree of success in achieving the established objectives and wastewater characteristics plays a major role in determining the stability in system performance especially in case of hydrogen production through anaerobic fermentation.

3. The hydrogen gas estimated showed higher variations throughout the experiment. The hydrogen production in the first two days was greater than $3.45 \mathrm{mmol} /$ day but the value decreased on the $3^{\text {rd }}$ day to $1.18 \mathrm{mmol} / \mathrm{day}$ indicating a possible system failure. However, the hydrogen values estimated from the anaerobic fermentation of the complex feed was greater than that estimated with the synthetic feed indicating the success of the optimization studies. This interest will be motivated by their broad field of application, ranging from their use in wastewater treatment tobiological hydrogen production. Implementation of these applications in our daily life will require the collaboration of biologists, chemists and engineers to integrate their knowledge from diverse fields.

\section{Acknowledgements}

The authors would like to thank the faculties and scientists of Acharya nagarjuna university and Indian Institute of Chemical Technology for supporting and extending their valuable time, technical assistance and guidance to this manuscript.

\section{References}

Ahring B.K., Angelidaki, I. (1997). Monitoring and controlling the biogas process. Proceedings at the $8^{\text {th }}$ international conference on anaerobic digestion, 25-29 May 1997, Sendai, Japan, 1: 40-50.

APHA-AWA-WPCF. (2000). Standard methods for the examination of water and wastewater, Washington, DC, American Public Health Association.

Bicelli L.P. (1986). Hydrogen A Clean Energy Sources. Fast J.HE 11.555-562.

Chudoba, P., Capdeville, B. and Chudoba, J. (1992). Explanation of biological meaning of the $\mathrm{S}_{0} / \mathrm{X}_{0}$ ratio in batch cultivation. Water Sci. Technol., 26: 743-775.

Fascetti, E. and Todini, O. (1995). Rhodobacter sphaeroides RV cultivation and hydrogen production in a oneand two-stage chemostat. Appl. Microbiol. Biotecnol. 44: 300-5.

Gibbs, M., Hollaender, A., Kok, B., Krampitz, L.O., and San Pietro, A. (1973). Proceedings of the workshop on Bio Solar Hydrogen Conversion. September 5-6 1973, Bethesda, MD.

Hillmer, P., Gest, H. (1977). $\mathrm{H}_{2}$ metabolism in photosynthetic bacterium Rhodopseudomonas ignocell: $\mathrm{H}_{2}$ production by growing cultures. J Bacteriol., 129(2): 724-731.

Khanal, S.K., Chen, W.H., Li, L. and Sung, S. (2004). Biological hydrogen production: effects of pH and intermediate products. Int. J. Hydrogen Energy, 29: 1123-1131.

Koku, Inci Eroglu, Ufuk Gunduz, Meral Yucel, Lemi Turker. (2003). Kinetics of biological hydrogen production by the photosynthetic bacterium Rhodobacter sphaeroides O.U.001. Int. J. Hydrogen Energy, 28: 381-388.

Kovacs, K.L, Kaman. (2000). Recent advances in biohydrogen research Europe physiol, 439 [suppl]: r 81 -r83.

Kumar, N., and Das, D. (2001). Continuous hydrogen production by immobilized Enterobacter cloacae IIT-BT 08 using ignocelluloses material as solid matrices. Enzyme Microbial Technol., 29: 280-7.

Ueno, Y., Kawai, T., Sato, S., Otsuka, S. and Morimoto, M.J. (1995). Biological production of hydrogen from cellulose by natural anaerobic microflora. Ferment. Bioeng. 4: 79, 395.

Venkata Mohan S, K Krishna Prasad, N Chandrasekhar Rao, Y Vijaya Bhaskar, V Lalit Babu, PN Sarma. (2005). Biological treatment of low-biodegradable composite chemical wastewater using upflow anaerobic sludge blanket (UASB) reactor: process monitoring. Journal of Scientific and Industrial Research (Revised). 
Table 1. Synthetic feed composite

Table 2. Complex feed composition

\begin{tabular}{|c|c|}
\hline Nutrients & Composition $(\mathrm{g} / \mathrm{l})$ \\
\hline $\mathrm{NH}_{4} \mathrm{Cl}$ & 0.5 \\
\hline $\mathrm{KH}_{2} \mathrm{PO}_{4}$ & 0.25 \\
\hline $\mathrm{K}_{2} \mathrm{HPO}_{4}$ & 0.25 \\
\hline $\mathrm{MgCl}_{2} \cdot 6 \mathrm{H}_{2} \mathrm{O}$ & 0.3 \\
\hline $\mathrm{FeCl}_{3}$ & 0.025 \\
\hline $\mathrm{NiSO}_{4}$ & 0.016 \\
\hline $\mathrm{CoCl}_{2}$ & 0.025 \\
\hline $\mathrm{ZnCl}_{2}$ & 0.0115 \\
\hline $\mathrm{CuCl}_{2}$ & 0.0105 \\
\hline $\mathrm{CaCl}_{2}$ & 0.005 \\
\hline $\mathrm{MnCl}_{2}$ & 0.015 \\
\hline Glucose $\left(\mathrm{C}_{6} \mathrm{H}_{12} \mathrm{O}_{6}\right)$ & 3 \\
\hline
\end{tabular}

\begin{tabular}{|c|c|}
\hline \multicolumn{1}{|l|}{ Nutrients } & Composition (g/l) \\
\hline Di- Ammonium Phosphate & 0.5 \\
\hline $\mathrm{MgCl}_{2} .6 \mathrm{H}_{2} \mathrm{O}$ & 0.3 \\
\hline $\mathrm{FeCl}_{3}$ & 0.025 \\
\hline $\mathrm{NiSO}_{4}$ & 0.016 \\
\hline $\mathrm{CoCl}_{2}$ & 0.025 \\
\hline $\mathrm{ZnCl}_{2}$ & 0.0115 \\
\hline $\mathrm{CuCl}_{2}$ & 0.0105 \\
\hline $\mathrm{CaCl}_{2}$ & 0.005 \\
\hline $\mathrm{MnCl}_{2}$ & 0.015 \\
\hline Sucrose $\left(\mathrm{C}_{11} \mathrm{H}_{22} \mathrm{O}_{11}\right)$ & 3.74 \\
\hline
\end{tabular}

Table 3. Kinetic Model Parameters

\begin{tabular}{|c|c|c|c|c|c|c|c|c|c|}
\hline Time $(\mathrm{hrs})$ & Hydrogen $(\mathrm{ml} / \mathrm{hr})$ & $\mathrm{VSS}(\mathrm{g} / \mathrm{L})$ & $\mu\left(\mathrm{hr}^{-1}\right)$ & $\mathrm{k}_{\mathrm{c}}\left(\mathrm{hr}^{-1}\right)$ & $\mathrm{k}_{\mathrm{s}}\left(\mathrm{hr}^{-1}\right)$ & $\mathrm{Y}$ & $\mathrm{r}_{\mathrm{g}} *\left(10^{-3}\right)(1 / 1 / \mathrm{hr})$ & $\mathrm{r}_{\mathrm{g}}^{\mathrm{c}} * 10^{-3}(\mathrm{l} / \mathrm{g} / \mathrm{hr})$ & $\eta$ \\
\hline 0 & 0 & 0.8 & - & - & - & - & - & - & 0 \\
\hline 2 & 3.15 & 1.2 & 0.2 & 0.21 & 1.16 & 1.15 & 2.52 & 7.88 & 0.91 \\
\hline 4 & 2.64 & 5.2 & 0.47 & 0.58 & 0.81 & 0.11 & 2.11 & 0.6 & 1.51 \\
\hline 6 & 4.08 & 5.7 & 0.33 & 0.42 & 0.66 & 0.1 & 3.26 & 0.83 & 2.34 \\
\hline 8 & 6.51 & 8.6 & 0.3 & 0.44 & 0.49 & 0.068 & 5.21 & 0.88 & 3.73 \\
\hline 10 & 8.93 & 9.8 & 0.25 & 0.39 & 0.46 & 0.056 & 7.14 & 0.99 & 5.12 \\
\hline 12 & 11.1 & 10.4 & 0.21 & 0.34 & 0.24 & 0.05 & 8.88 & 1.16 & 6.34 \\
\hline 24 & 1.84 & 27.2 & 0.15 & 0 & 0.16 & 0.02 & 1.47 & 0.07 & 6.34 \\
\hline
\end{tabular}

Table 4. Details of hydrogen production from the experimental study

\begin{tabular}{|l|l|l|l|}
\hline S. No & Industrial Wastewater & $\begin{array}{l}\text { Organic loading rate (OLR) } \\
(\mathrm{Kg} \mathrm{COD} / \text { cum-day) }\end{array}$ & Hydrogen Production (mmol/day) \\
\hline 1 & Designed synthetic wastewater & 3.80 & 0.486 \\
\hline 2 & Designed complex wastewater & 4.67 & 3.45 \\
\hline
\end{tabular}




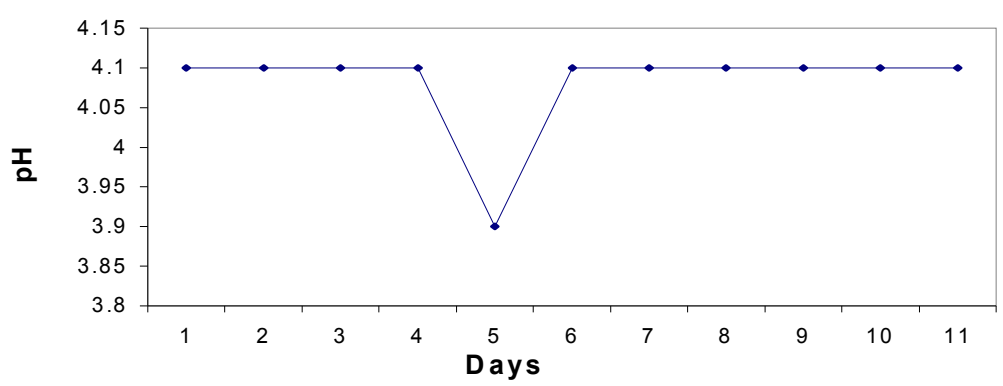

Figure 1. Study state condition of $\mathrm{pH}$ in a suspended growth reactor

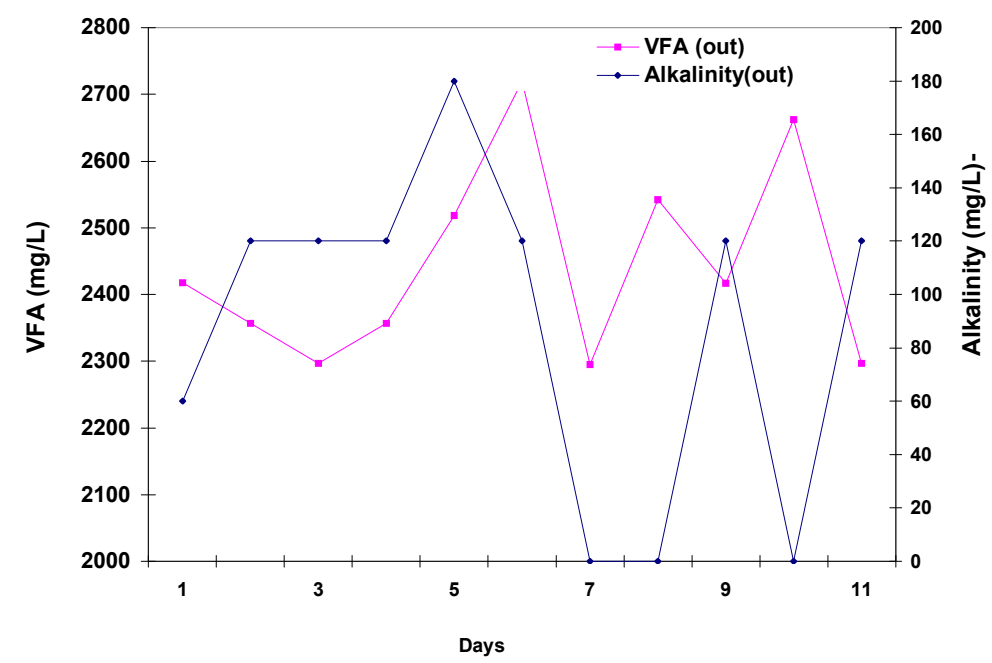

Figure 2. Variation of VFA-concentration and alkalinity of inlet and outlet of synthetic feed at different HRT

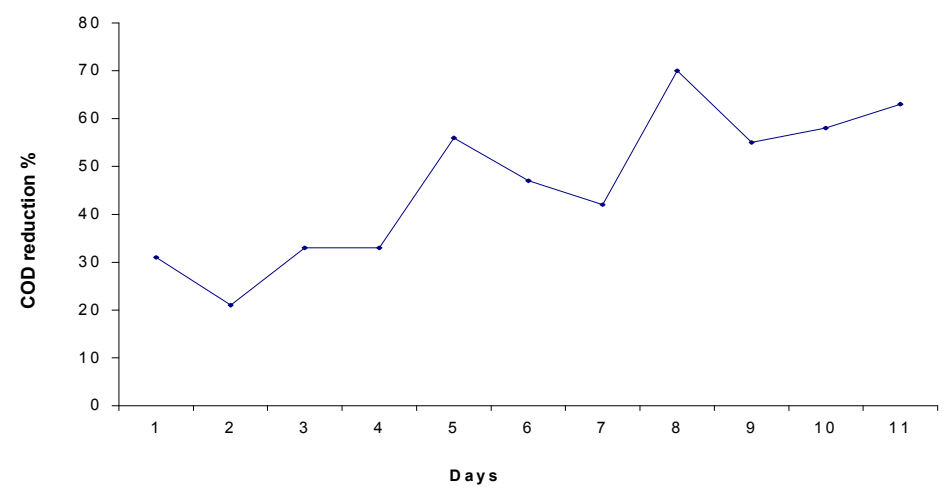

Figure 3 . The $\%$ of COD reduction values in the experimental period at different HRT 


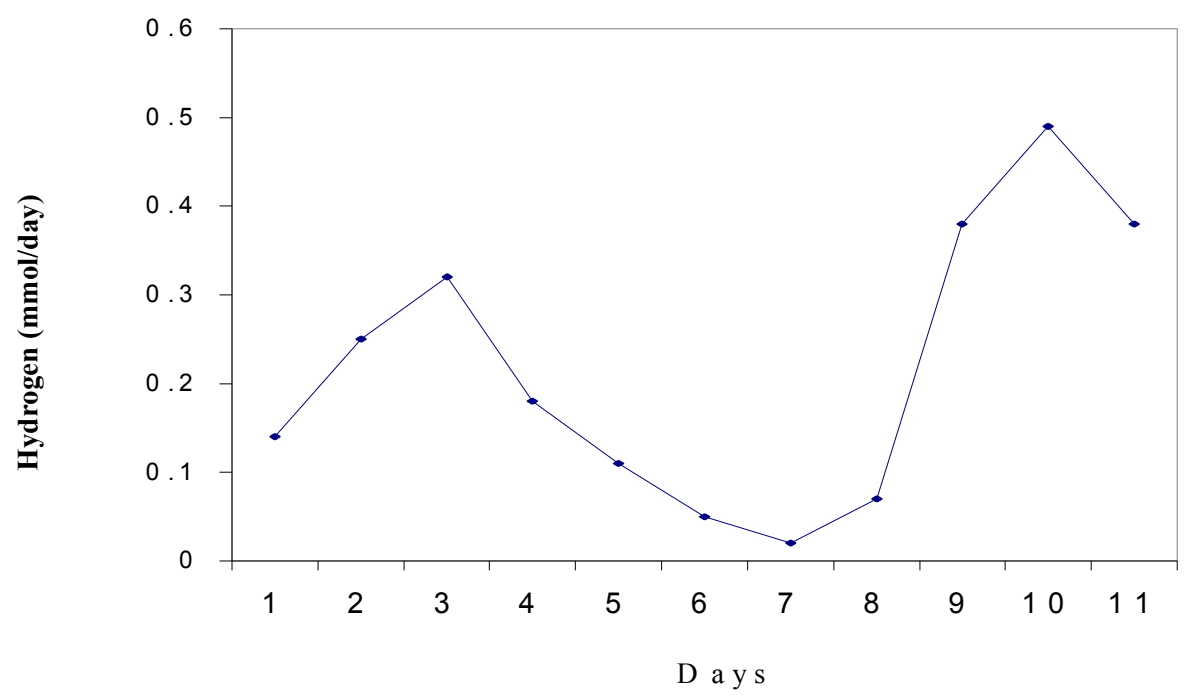

Figure 4. Variation of hydrogen production rate at different HRT

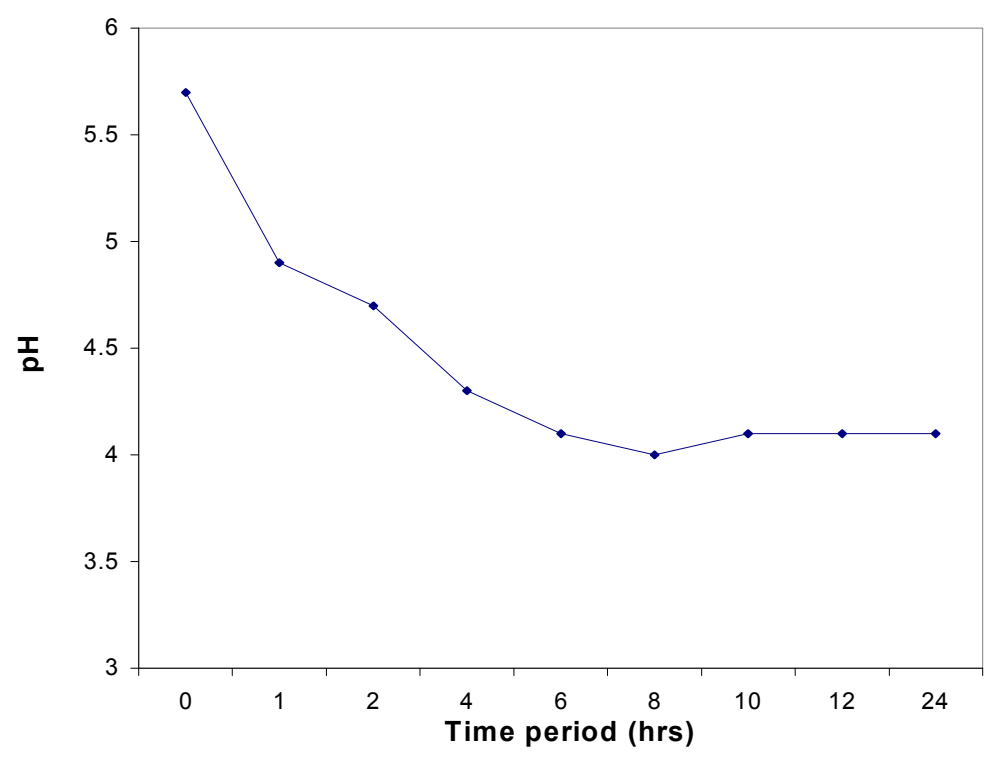

Figure 5. Variation of $\mathrm{pH}$ of synthetic feed at different HRT

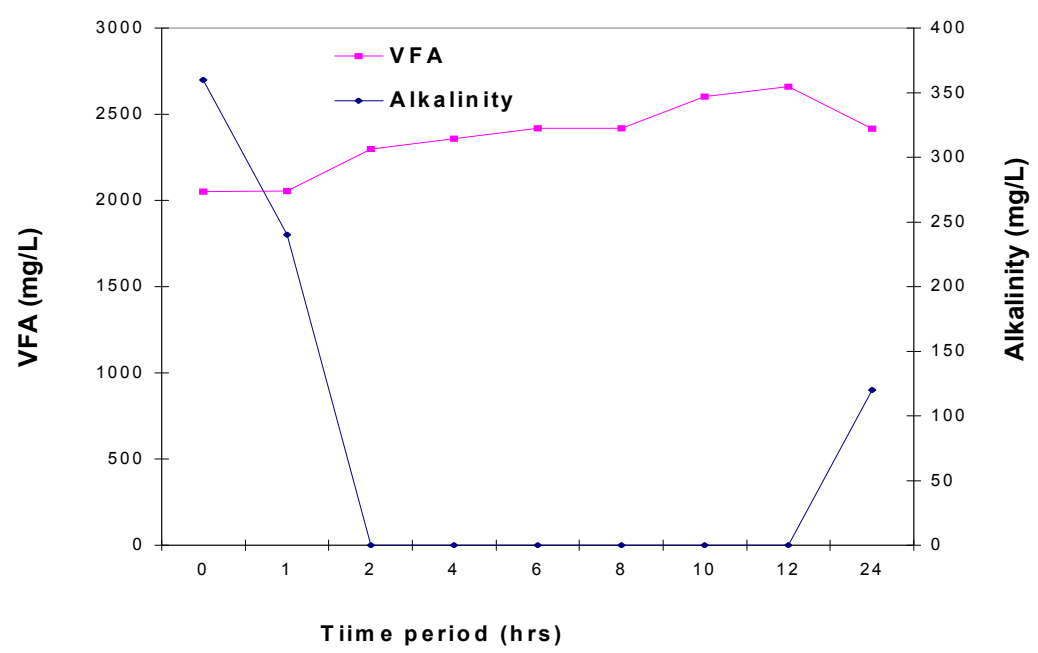

Figure 6. Variation of VFA-concentration and alkalinity of inlet and outlet of synthetic feed at different HRT 


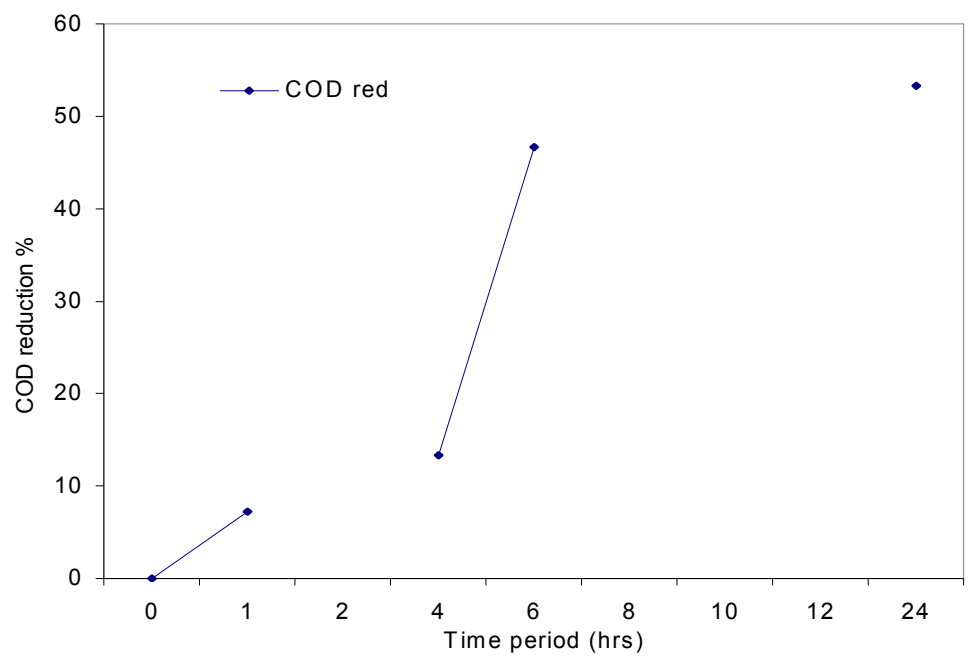

Figure 7. The $\%$ of $\mathrm{C}$ OD reduction values in the experimental period at different HRT

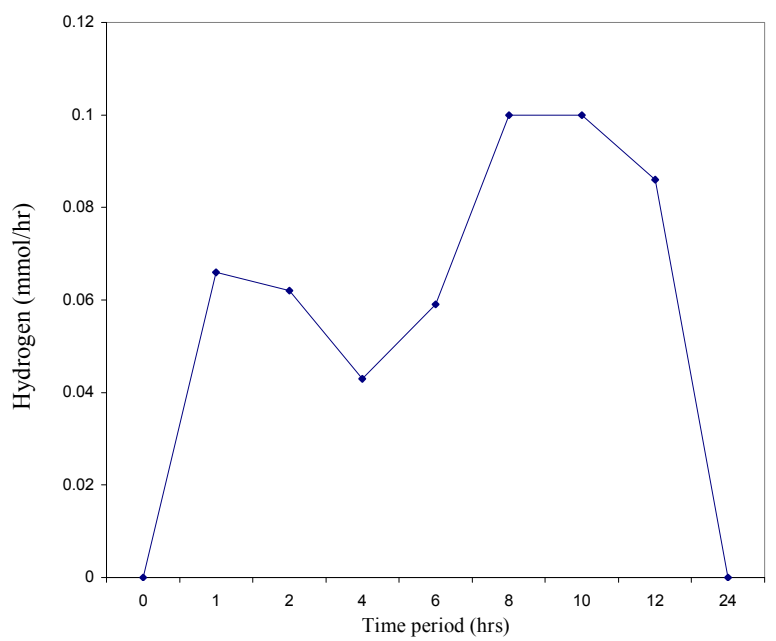

Figure 8. Variation of hydrogen production rate at different HRT

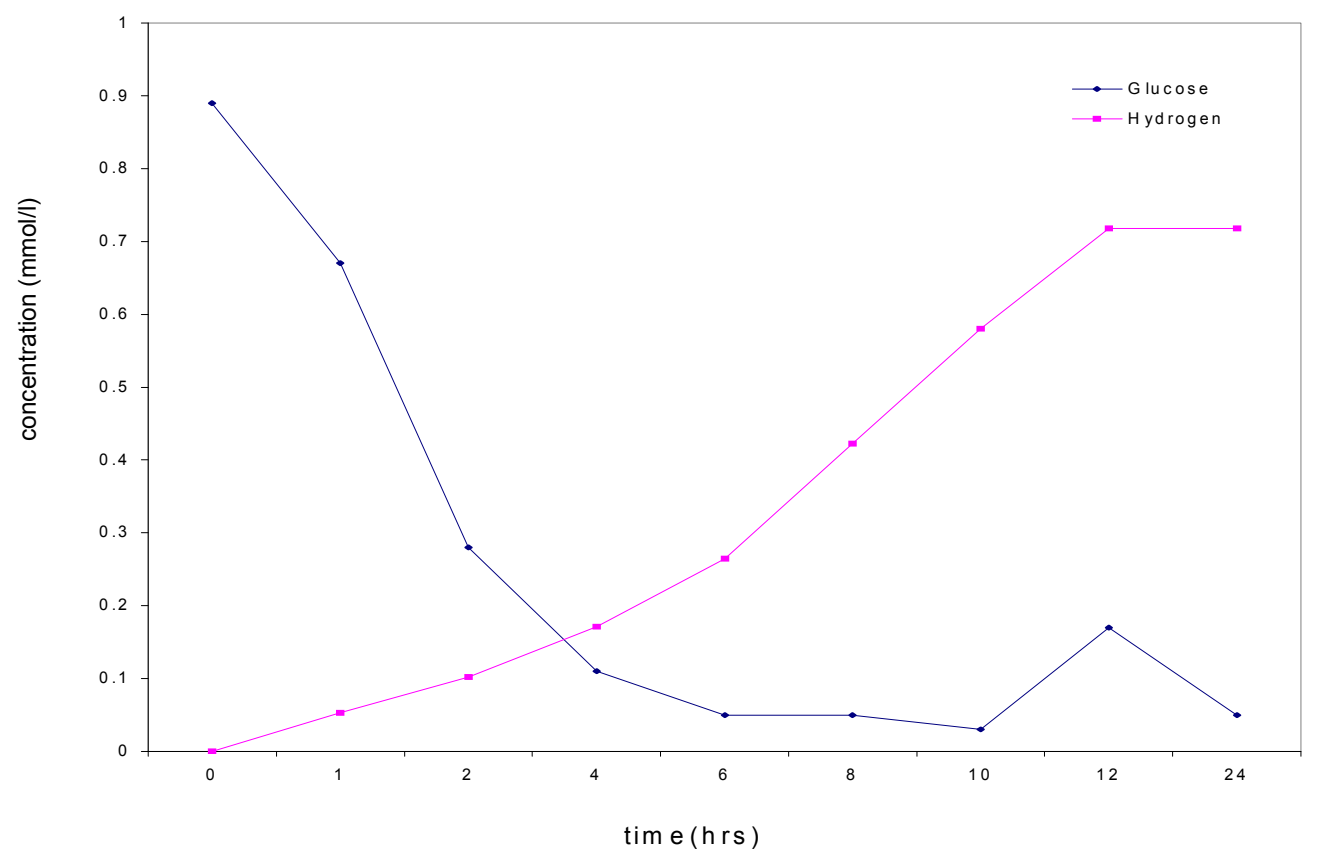

Figure 9. Hydrogen concentration and glucose utilization with time 


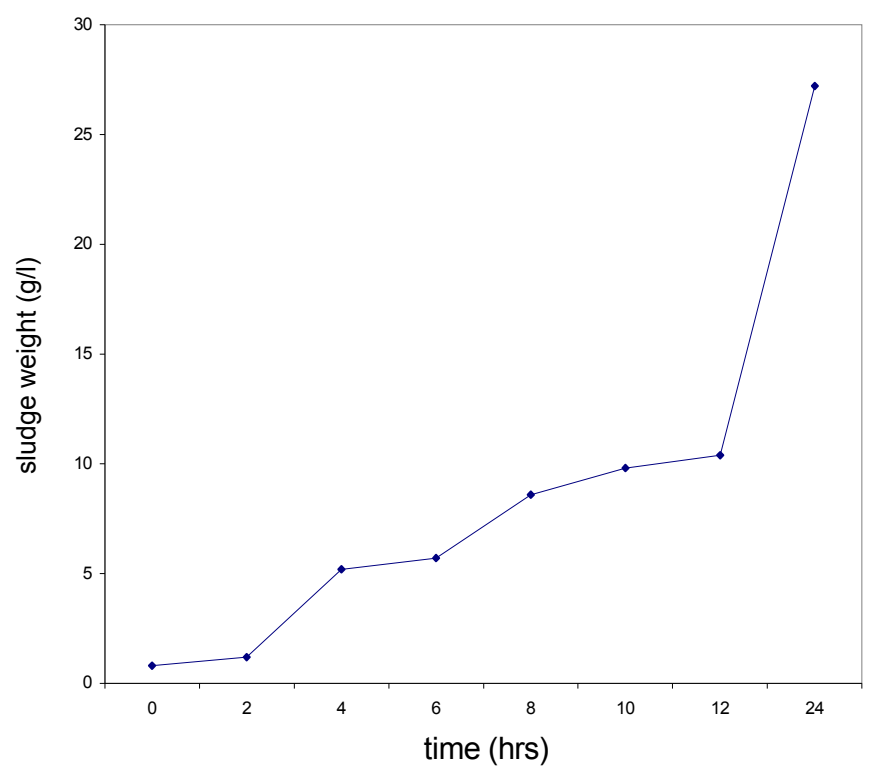

Figure 10. Variation of sludge weight with different HRTs

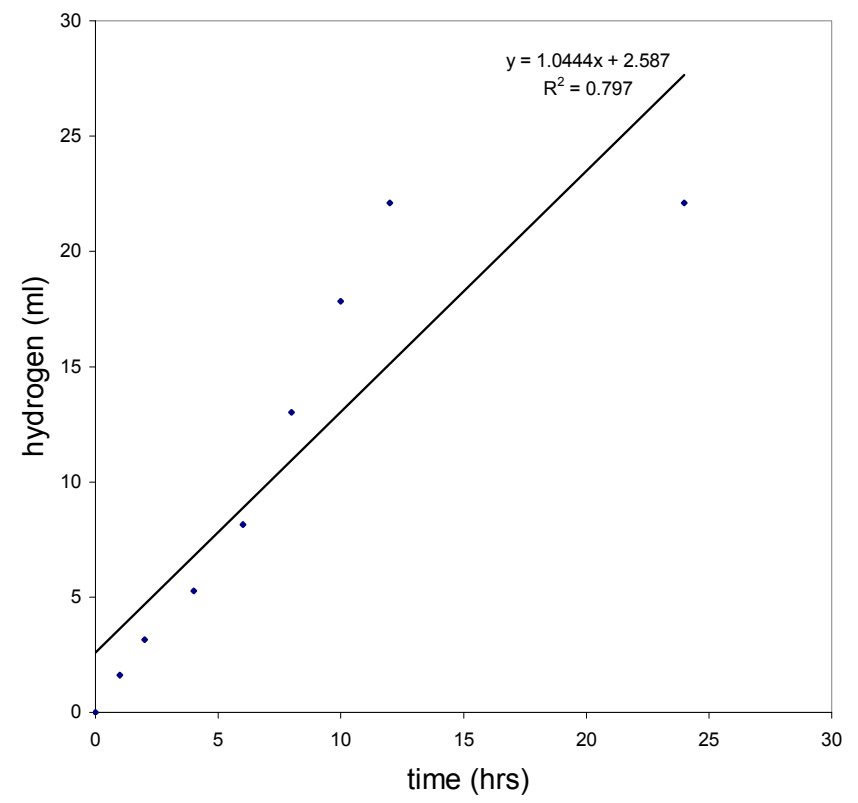

Figure 11. Variation of hydrogen production with different HRT 


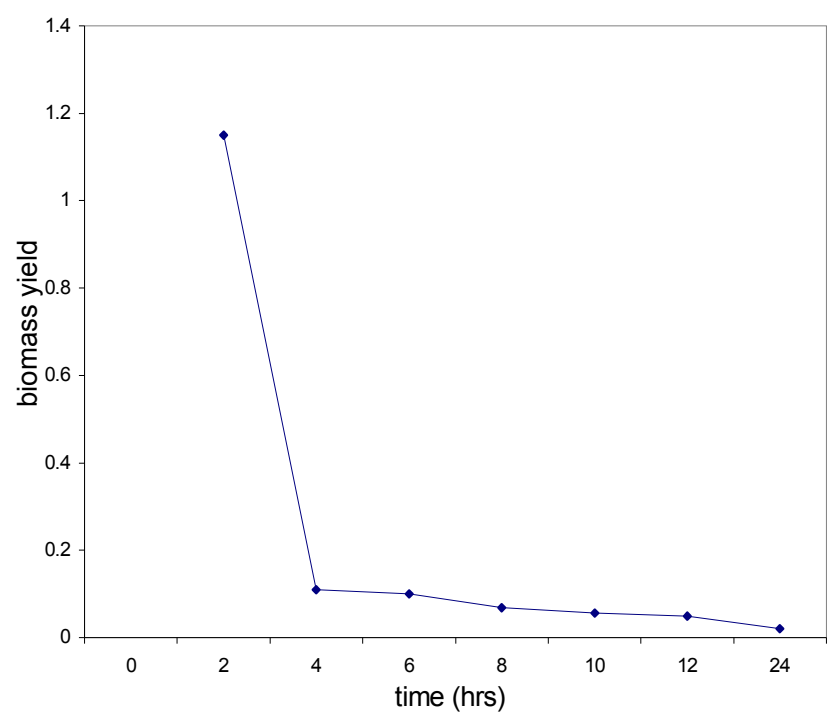

Figure 12. Variation of biomass with different HRT

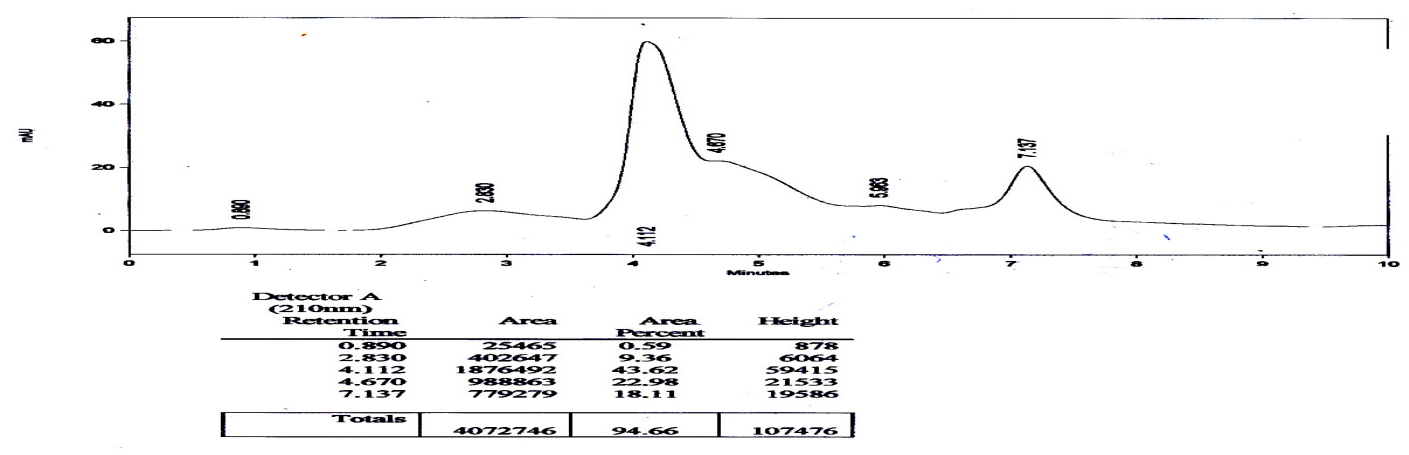

Figure 13. VFA- Evaluation through High power liquid chromatography spectrum

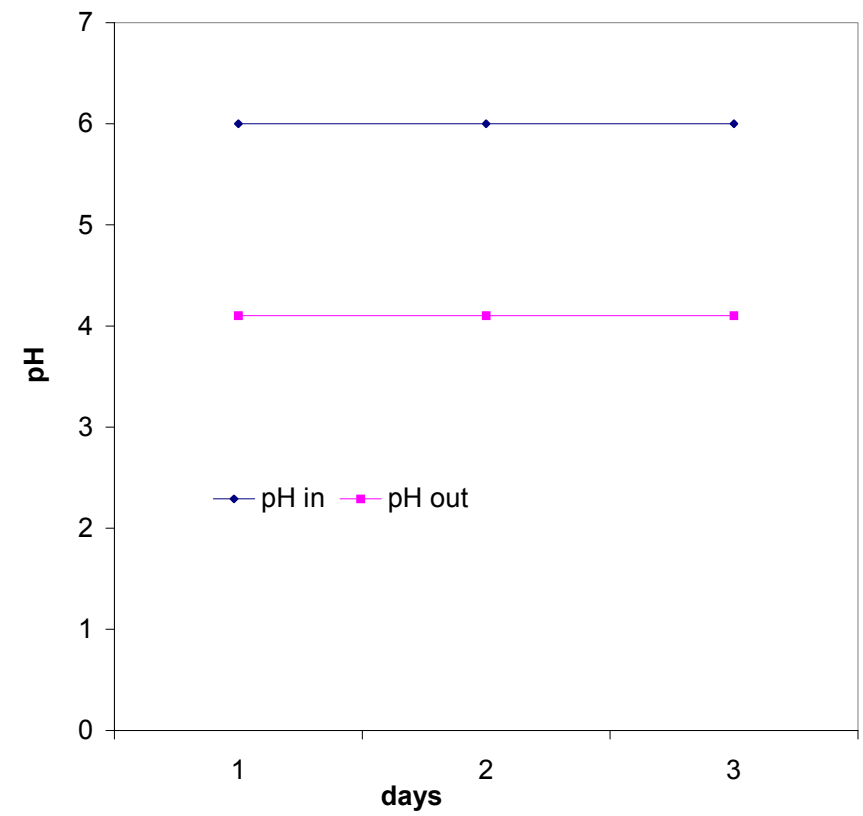

Figure 14. $\mathrm{pH}$ values of inlet and outlet of complex feed at different HRT 


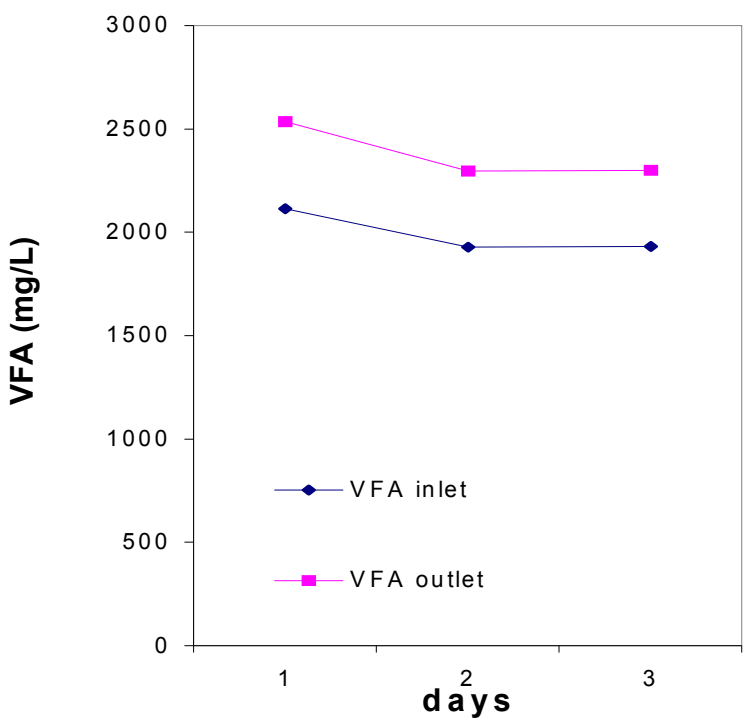

Figure 15. Variation of VFA-concentration of inlet and outlet of complex feed at different HRT

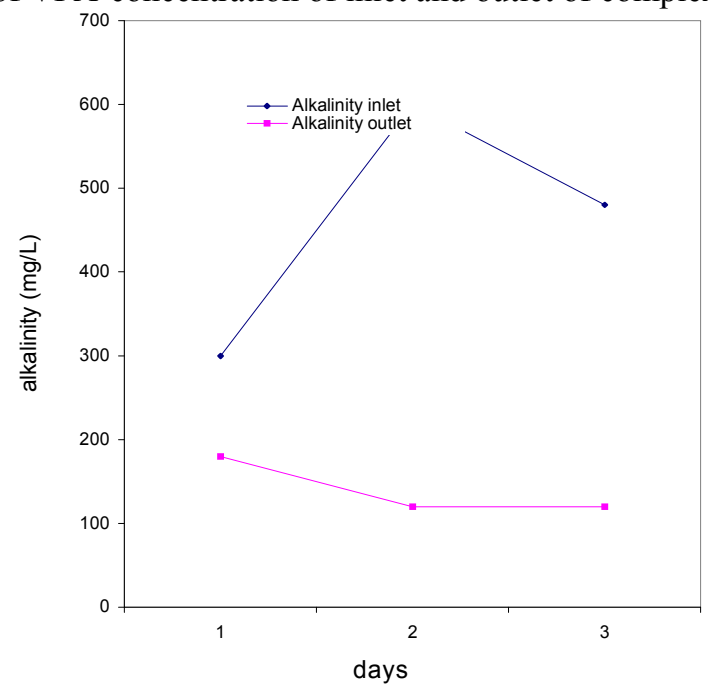

Figure 16. Variation of alkalinity of inlet and outlet complex feed at different HRT

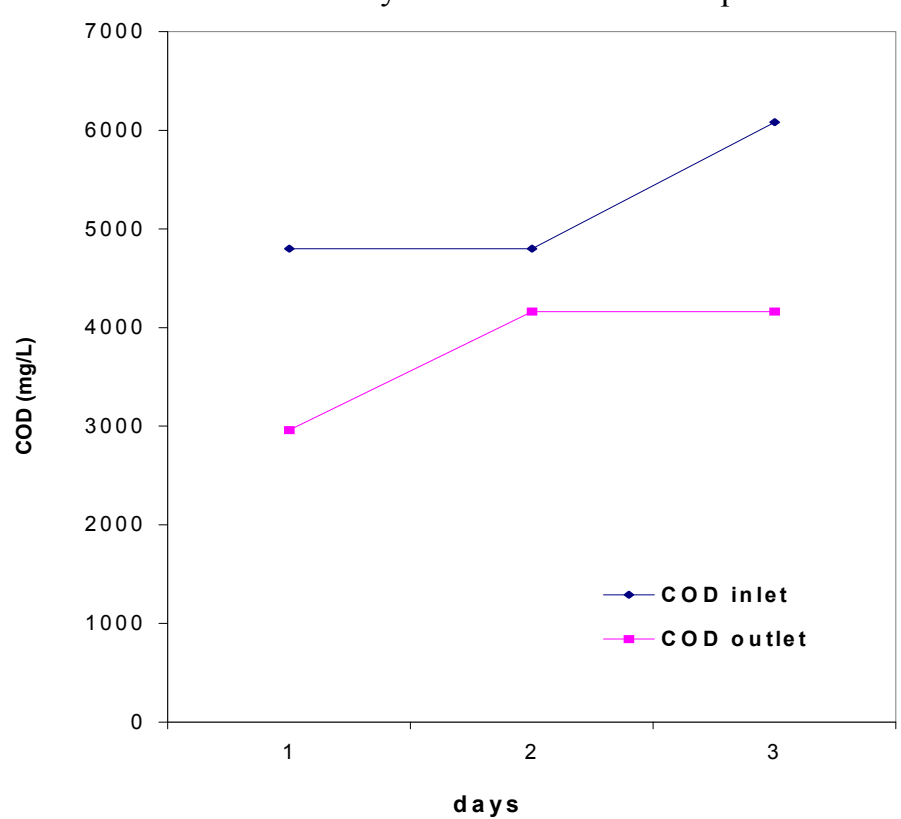

Figure 17. Variation in COD values of complex feed at different HRT 


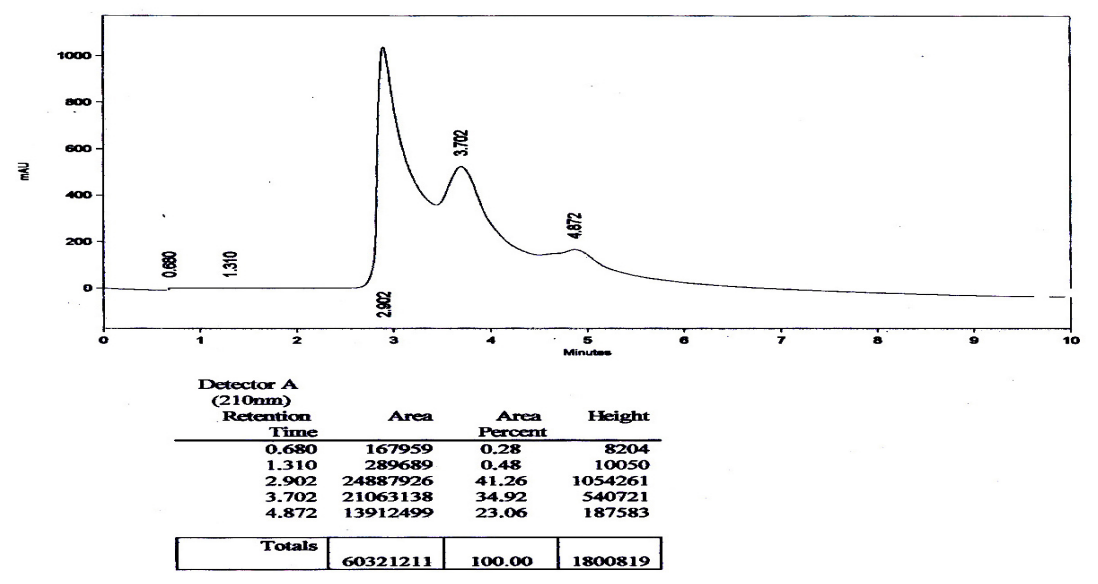

Figure 18. VFA Evaluation through High power liquid chromatography spectrum

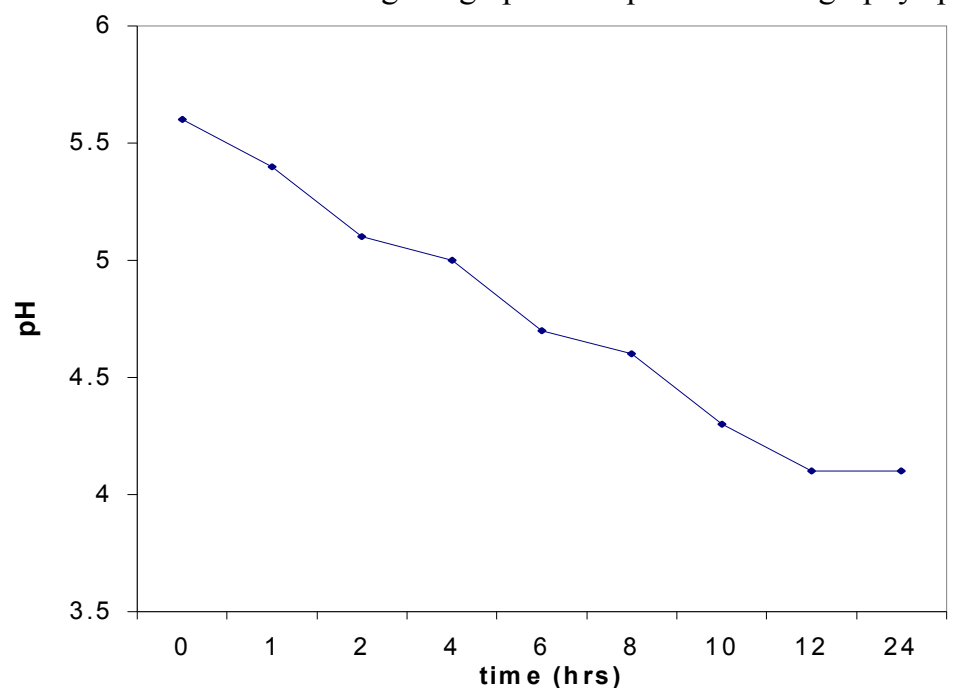

Figure 19. Variation of $\mathrm{pH}$ of complex feed at different HR

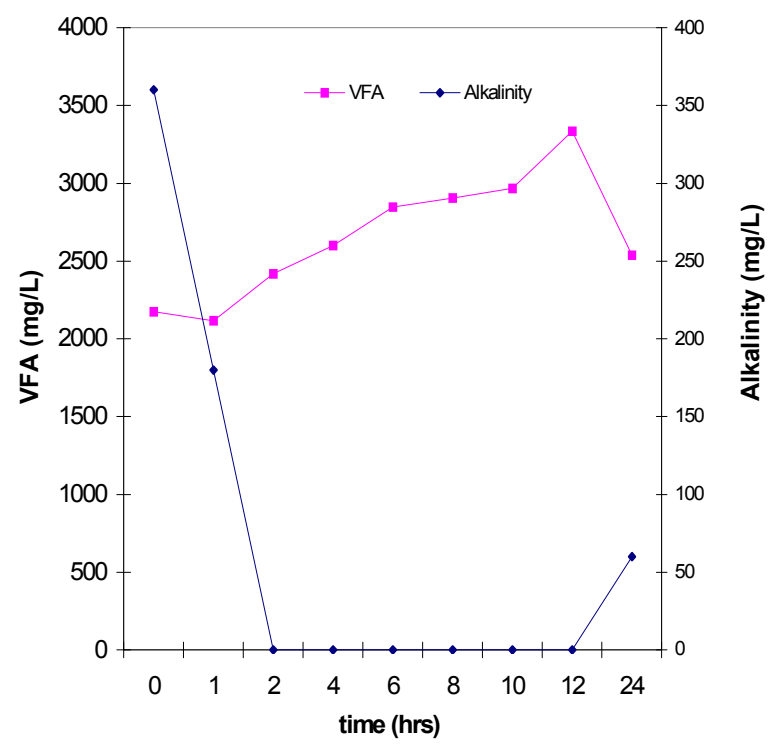

Figure 20. Variation of VFA-concentration and alkalinity of inlet and outlet of complex feed at different HRT 


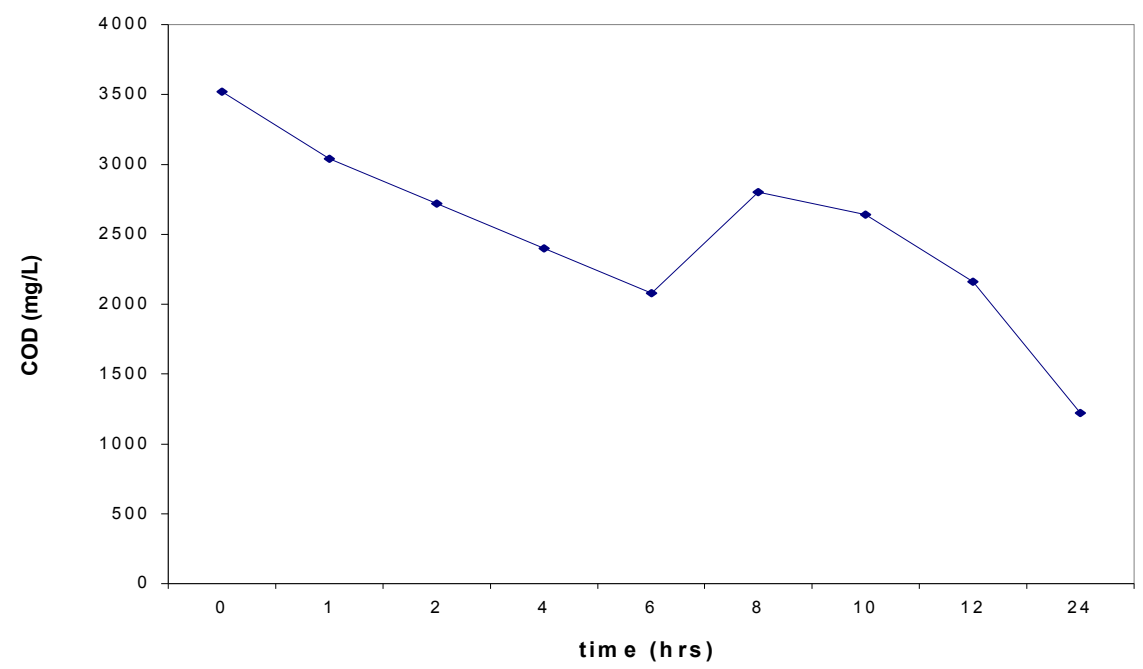

Figure 21. Variation in COD values of complex feed at different HRT

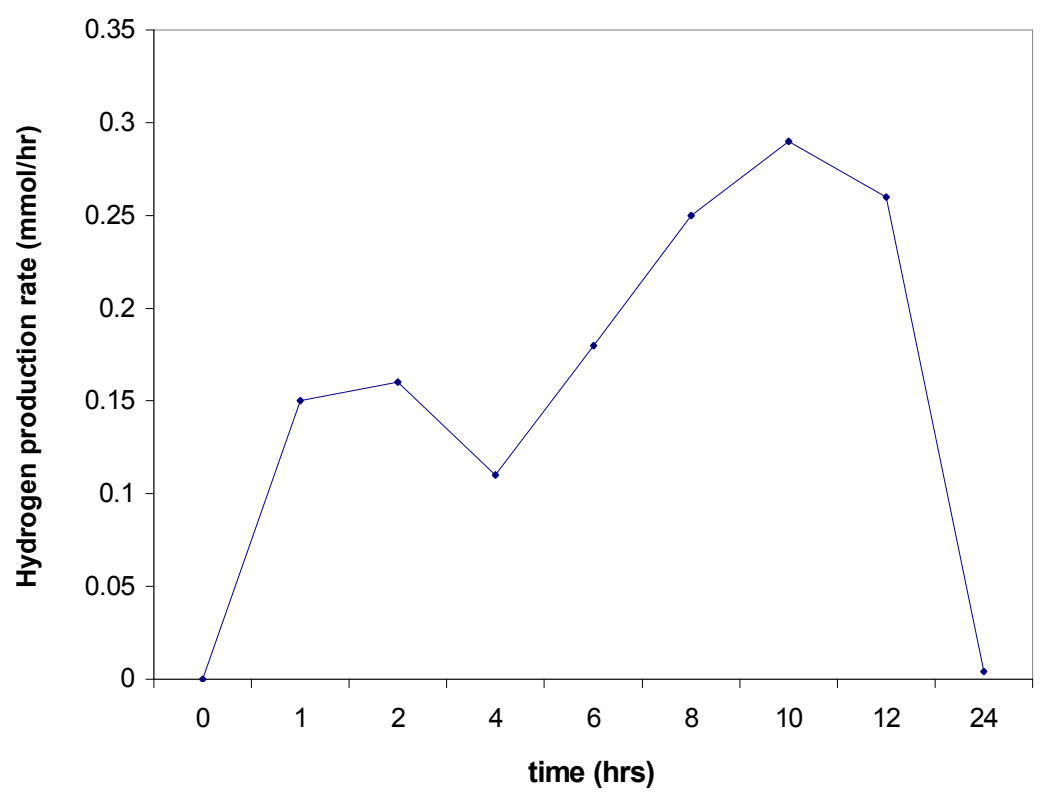

Figure 22. Variation of hydrogen production rate at different HRT 